\title{
SURGICAL TIP
}

\section{Precision blepharoplasty - Let your fingers do the tautening}

Michael SG Bell MD FRCSC

Tn performing a blepharoplasty, great care is always taken to 1 precisely mark the exact incision line. Different techniques are described for this, but everyone has a system that is individually comfortable for them, and variable to the patient's problem. Translating this careful ink mark into an incision is an additional challenge that we all face.

Eyelid skin is exceedingly mobile, and redundant inelastic skin is even more mobile, requiring special efforts for countertraction when incising with a blade.

Slight overdistention of the skin with local anaesthetic is helpful, but the most effective means of countertraction I have found is the simple secretary's rubber finger cot.

This finger cot embodies the right texture with its fine rubber knobs, so that it has a high degree of friction to prevent the skin from sliding (Figure 1). That makes it superior to the standard operating room gloves for countertraction.

These devices autoclave perfectly well and are reusable. They offer a significant improvement in control for accomplishing the precise incisions required in blepharoplasty. They can also be used to atraumatically handle large slippery skin flaps.

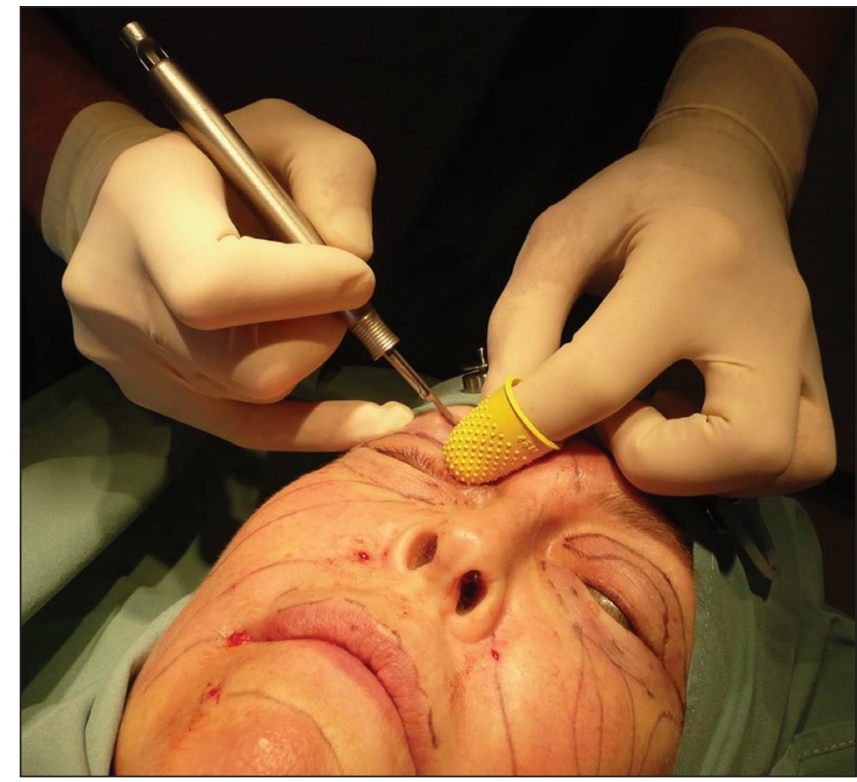

Figure 1) Using a secretary's finger cot to apply countertraction

The Department of Surgery, Division of Plastic Surgery, The Ottawa Hospital-Civic Campus, Ottawa, Ontario

Correspondence: Dr Michael SG Bell, 402-1919 Riverside Drive, Ottawa, Ontario K1H 1A2. Telephone 613-739-5424, fax 613-739-7168, e-mail msgbell@cyberus.ca 